\title{
COMUNICACIÓN ORGANIZACIONAL
}

\section{CLAUDIA LILIANA BENITTEZ}

FACULTAD DE ESTUDIOS A DISTANCIA PROGRAMA DE ADMINISTRACIÓN DE EMPRESAS BOGOTÁ D.C.

2014 
COMUNICACIÓN ORGANIZACIONAL

CLAUDIA LILIANA BENÍTEZ

Presentado a: NORMA CONSTANZA DÍAZ

FACULTAD DE ESTUDIOS A DISTANCIA

PROGRAMA DE ADMINISTRACIÓN DE EMPRESAS BOGOTÁ D.C. 2014 


\section{CONTENIDO}

$>$ INTRODUCCIÓN

$>$ SU PROCESO A TRAVÉS DE LA HISTORIA

$>$ CONCEPTO

$>$ CARACTERÍSTICAS

D HERRAMIENTAS DE LA COMUNICACIÓN ORGANIZACIONAL

$>$ CONCLUSIONES

$>$ REFERENCIAS Y BIBLIOGRAFÍA 


\section{COMUNICACIÓN ORGANIZACIONAL}

\section{INTRODUCCION}

En el desarrollo de este ensayo escrito, abordaremos la importancia, antecedentes y repercusión de la comunicación organizacional en las empresas y su desarrollo corporativo. Si bien las ganancias de una empresa están dadas por el buen desarrollo de su actividad comercial, existen elementos diferenciadores que determinan la recordación de marca y la consecución de las mismas. Uno de ellos es la comunicación organizacional.

Qué importancia tiene en el impacto comercial de una organización el buen uso y desarrollo de este elemento? Solo con el profundo análisis de su uso en la historia y su incidencia en la totalidad de la estructura interdepartamental de las compañías podremos entender de su alto índice de efectividad en el correcto curso de los objetivos y misiones propuestas de toda sociedad.

Para abordar el tema y tener una idea completamente clara de lo que significa la comunicación organizacional en las empresas, se requiere de una correcta conceptualización de lo que significa "organización" en el ámbito corporativo. No basta con el concepto abstracto y metódico que por sentido común se maneja en la cotidianidad, se debe contemplar el margen global de su significado.

Una organización es un conjunto totalmente empalmado, sellado, en completo enlace y con un mínimo de riesgo de error. Este concepto se construye con la investigación y análisis de varias perspectivas en el área de trabajo a desarrollar y es el concepto que nos permitirá mantener la ruta del desarrollo de nuestro resultado investigativo.

Cuál es los antecedentes que permitieron el desarrollo de la comunicación organizacional? Cuáles son los componentes principales que permiten el buen desarrollo de la misma en las empresas?, en general, Que influyó y que avances aporta hoy en día a la sociedad y promoción empresarial?. En el transcurso de la lectura, entenderemos y notaremos el importante vínculo de cada uno de los propósitos de este escrito, a la vez que llevaremos nuestros conceptos a una nueva visión que nos permitirá desarrollar el buen uso de la comunicación en nuestro desarrollo profesional. 


\section{SU PROCESO A TRAVÉS DE LA HISTORIA Y SU IMPORTANCIA EN LA ACTUALIDAD}

En los escritos de Julio César como en la obra "La guerra de las Galias" se encuentra una mirada especifica de la función de su Imperio que se podría comparar a modos de Comunicación Institucional de nuestros tiempos. La difusión de ideas en la sociedad siempre ha estado presente. Lo que ha variado es el modo de realizarse a lo largo de la historia.

La propagación institucional de las ideas, presente en la sociedad desde sus orígenes, adquirió con la creación de la imprenta un impulso decisivo, pues era un medio con una enorme capacidad de difusión. Las protagonistas de las luchas religiosas y políticas que tuvieron lugar en Europa aprovecharían la imprenta para difundir de modo masivo sus ideas y opiniones frente a los adversarios.

La prensa se desarrollaría progresivamente provocando que la difusión organizada de ideas adquiriera un papel cada vez mayor, primero en las guerras europeas, y más tarde en la Revolución Francesa (1789), en el nacimiento de los Estados Unidos, en el desarrollo de los nacionalismos del siglo XIX y en la unificación de países como Italia (1870).

El desarrollo económico-industrial y los adelantos científicos provocaron el descubrimiento de nuevos medios de comunicación con un potencial de difusión extraordinario: primero la radio en los años 20, después la televisión en la década de los años 40 y más adelante la tecnología digital o internet. Estos medios configuraron una nueva sociedad, la sociedad de la información, dando vida a una cultura global y situando a los medios de comunicación en el centro del debate político, religioso, comercial e ideológico de todo el siglo XX.

Después de 1945 la Comunicación Institucional se consolida como actividad profesional en el mercado de la información por: Internacionalización de la práctica de la Comunicación institucional, aparición de literatura científica y técnica, proliferación de profesionales, estabilización del número de empresas, cursos de comunicación institucional en universidades y más profesionales con formación superior. 
Antes del de 1945 la Comunicación Institucional estaba ligada a la propaganda. Como es el caso del gobierno de Adolf Hitler, que había sentido la derrota de su Alemania contra los gobiernos Británicos y estadounidense, en su celda reflexionaba el motivo por cual fue la derrota fue gracias al manejo inteligente de la propaganda por

parte de dichos gobiernos, encargados de elaborar y divulgar la propaganda.

Los mensajes contenían informes sobre las inescrupulosas crueldades impartidas contra los civiles y prisioneros de guerra; el objetivo de esta era "fortalecer la resolución de luchar y convencer a los ciudadanos de la moralidad de la guerra".

Otra técnica utilizada fue correr informaciones de que los científicos alemanes estaban por dar terminado dos armas modernas, un submarino de gran velocidad y misiles que podian guiarse por electromagnetismo hacia los aviones enemigos, esto fue utilizado al ver derrota tras derrota, y con esto tratar de convencer que todavia se podía ganar la guerra.

La comunicación institucional tiene por tanto muchos y variados antecedentes históricos, pero en cuanto disciplina se ha desarrollado especialmente desde mediados del siglo XX, muy unida a la comunicación de empresas comerciales: éstas comenzaron a vender sus productos a gran escala -especialmente en Estados Unidosy vieron la oportunidad de comunicar con sus clientes de un modo masivo a través de las múltiples fórmulas comunicativas que ofrecían los nuevos medios.

\section{CONCEPTO}

Según lo estudiado en el paso de la historia, el concepto de comunicación institucional surge a raíz de la gran importancia que existía por el análisis de las instituciones y del interés en la sociedad actual.

Se puede definir a la Comunicación Institucional como "El Sistema Coordinador entre la Institución y sus Públicos que Actúa para Facilitar la Consecución de los Objetivos Específicos de Ambos y, a través de ello, Contribuir al Desarrollo Nacional." (3)

MURIEL)

Es considerado un sistema a la unidad de análisis de la teoría de sistemas, perspectiva teórica que nació a raiz de un interés creciente con el fin de la unificación de las ciencias. La idea central de sistemas es el concepto de interdependencia que está siempre presente entre los diversos elementos que constituyen cualquier sistema. 
En resumen un sistema es un Conjunto de Elementos Interrelacionados que Opera para Lograr un Objetivo Común.

Según el autor José María La Porte en su artículo "Perspectivas sobre Comunicación" define a la comunicación Institucional puede definirse "como el tipo de comunicación realizada de modo organizado por una institución o sus representantes, y dirigida a las personas y grupos del entorno social en el que desarrolla su actividad. (4) LA PORTE)

Tiene como objetivo establecer relaciones de calidad entre la institución y los públicos con quienes se relaciona, adquiriendo una notoriedad social e imagen pública adecuada a sus fines y actividades.

\section{CARACTERISTICAS}

Las características de la comunicación institucional pueden destacarse las siguientes:

La comunicación institucional está relacionada con el marketing, la publicidad y las relaciones públicas, pero va más allá de las funciones realizadas por ellas, pues busca transmitir la personalidad de la institución y los valores que la fundamentan. La comunicación institucional tiene un carácter dialógico porque busca relacionarse con los miembros de la sociedad en la que está presente, tanto individuos como instituciones, contribuyendo al bien común a través de sus fines específicos. No puede separarse la identidad de una institución, sus valores, del modo de comunicar. Su identidad debe estar en armonía con el contenido, con el modo y con la finalidad de su comunicación. ${ }^{*}(6$ (Intercontinental. $\left.)\right)$

Las instituciones son responsables de sus acciones ante la sociedad y su comunicación debe tener muy en cuenta esa responsabilidad. Existen tres posibles imágenes -que no siempre coinciden- en la comunicación de una institución: la imagen que se desea dar, la imagen real de la institución y la imagen percibida. Una buena comunicación institucional busca la armonia entre las tres imágenes procurando que se identifiquen, y evitando que la imagen que se comunica no corresponda con la realidad o que la institución sea percibida de un modo equivoco y que la percepción no coincida con la realidad.

La comunicación institucional no se identifica solamente con la información ofrecida por quienes coordinan las actividades comunicativas en la empresa. Hay un tipo de comunicación institucional formal que es la que realizan quienes han sido oficialmente designados para ello. Hay otro tipo de comunicación que es informal: la que transmiten quienes forman la institución con su modo de actuar y proceder, ya que aunque no estén investidos de autoridad son percibidos como parte representativa de la organización. Todo acto realizado por la institución tiene, por tanto, una repercusión 
social que muchas veces es interpretada por la sociedad como comunicación institucional.

La comunicación institucional tiende a gestionar todos los contactos comunicativos de la institución y sus miembros con los diversos públicos, sean públicos externos o internos.

Según las autoras Maria L. Muriel y Gilda Rota *(2) la Comunicación institucional facilita al gobierno en general y a las instituciones en particular el conseguir lo objetivos específicos que son parte de su objetivo primordial: el Bienestar Común. Considerando que los objetivos generales del bienestar común conllevan al logro de un desarrollo nacional. * ( (3) MURIEL))

Los objetivos más importantes que la Comunicación institucional puede permitir alcanzar y que contribuyen al logro de las metas de desarrolio nacional son:

- Unificación interna de cada institución.

- Relación de la labor de las diferentes instituciones entre sí.

- Coherencias entre los planes, programas y actividades de cada institución con respecto a los demás.

- Propagación de información en el sistema social para la reducción de la incertidumbre de individuos y de otras instituciones.

- Definición y legalización de los objetivos nacionales de desarrollo.

- Contribución para el logro de una conducta social organizada, especialmente en relación con las metas de desarrollo.

- Creación de un clima necesario para el cambio social organizado.

- Facilidad en la consecución de sus objetivos especificos en forma tal que sean congruentes con los objetivos nacionales de desarrollo, propicien la armonía entre los componentes del sistema social y hagan posible el equilibrio entre sus actividades particulares y las de las demás instituciones.

La comunicación Institucional se ocupa de mantener las adecuadas relaciones y comunicación de una organización, empresa, holding, o colectivo determinado, con sus distintos públicos, para la viabilidad y consecución de los objetivos.

La comunicación Institucional tienen por objeto analizar tendencias, predecir sus consecuencias, asesorar a la dirección de la organización, así como el establecimiento de programas de acción, que sirvan tanto al interés de la misma, como al de sus públicos: accionistas, entidades bancarias, personal, cliente, proveedores, otros.

Las diversas funciones de la comunicación nos muestran que no existe verdaderamente empresa sin proyecto, ni proyecto sin comunicación que estimule su realización.

Comunicar el proyecto es un acto simbólico de la Dirección General y no un simple 
discurso. Un acto que enuncia la vocación de la empresa, llama a la participación interna real, a la movilización externa y se apoya en los valores clave en los que funda su ética de la empresa. (5) GUISASOLA)

La comunicación forma parte de la gestión porque:

- Crea unidad de la empresa.

- Es el nexo por el cual la empresa es Comunidad.

- Se constituye en palanca de cambio que transforma la cultura de empresa con el fin de realizar el proyecto.

- Figura, representación, semejanza y apariencia de una cosa. Llamemos imagen de la empresa a la opinión que el público se forma a través de informaciones y acontecimientos, actos y normas que responden a las realidades configurando una información positiva para el público.

- "La imagen de la empresa es al decir de Joan Costa la representación mental, en el imaginario colectivo, de un conjunto de atributos y valores que funcionan como un estereotipo y determinan la conducta y opiniones de esta colectividad".

- Clara y precisa debe de ser esta imagen y para esto son necesarios los elementos de comunicación funcionando adecuadamente para ser presentadas al público de una forma óptima para ser canalizadas.

A continuación se relacionan los elementos de comunicación que cada empresa puede suministrar al público para que puedan tener una opinión concreta sobre la empresa:

- Historia y evolución de la firma, a través de los años. Realizaciones de orden técnico o de investigación, que signifiquen un avance.

- Prestigio de sus directivos, técnicos y especialistas.

- Condiciones sociales en las que trabajan empleados $u$ obreros. Contribuciones sociales y económicas al bienestar de la comunidad. Prestigio que la empresa proporciona a la comunidad.

- Aportes culturales.

- Calidad en sus servicios o producción.

- Planes de realizaciones futuras.

- Opinión pública.

Se entiende como la posición mental adoptada, u opinión sustentada, por la mayoría del público sobre una idea, información o hecho. Conseguir una opinión pública favorable para la empresa es la meta definitiva para los fines de las relaciones públicas, ya que representa la imagen de la empresa que está constituida por lo que el público piense, lo que crea de la estructuración, finalidades, actos y actitudes. 
Las características de la situación geopolítica actual y la globalización de los mercados y las comunicaciones requieren de las organizaciones, con o sin fines de lucro, una atención especial al área de sus relaciones con los diferentes públicos.

Estas nuevas exigencias incluyen a la denominada "comunicación en situaciones de crisis" como parte de la realidad cotidiana de estas organizaciones y hacia ella se ha orientado la capacitación. *( (4) LA PORTE))

El campo de actuación se orienta, específicamente, al asesoramiento relativo a la administración integrada del proceso de comunicación de las organizaciones, entendiendo como tal a la determinación de objetivos, la fijación de politicas, el diseño de estrategias, el planeamiento, la programación, la evaluación y, eventualmente, la ejecución de las acciones comunicativas destinadas a contribuir al eficiente cumplimiento de la misión corporativa.

El proceso de comunicación de una organización es un fenómeno global, efectivo mediante acciones que se orientan sinérgicamente hacia públicos especificos, utilizando soportes adecuados conforme a las necesidades de cada caso en particular.

Una estrategia exitosa de comunicación no será, pues, el resultado de acciones aisladas de relaciones institucionales, lobbying, publicidad, promoción, diseño o marketing, sino de un todo coherente. Es por ello que cuento, de ser necesario, con la colaboración de especialistas en disciplinas como Diseño (gráfico, industrial, de interior, etc.), Publicidad, Promoción, Marketing, Periodismo, Estudios de Opinión, etc. *( (2) MURIEL)

La integración del análisis interdisciplinario nos permite realizar un completo diagnóstico de situación como base para prestar un servicio integral o particularizado en alguna de las siguientes áreas:

\section{Asesoramiento}

En el diseño de programas de Imagen y Comunicación Institucional destinados a mantener y afianzar el posicionamiento e imagen de empresas, organizaciones e instituciones, en sus entornos de interés.

Mantener relaciones con los medios de comunicación y contacto fluido con los redactores y columnistas de las publicaciones especializadas en temas del área de operación del cliente.

Asesorar al cliente en la organización y ejecución de campañas y acciones de prensa.

Planificar y ejecutar acciones de prensa para esclarecer a la opinión pública sobre los productos y servicios del cliente.

Asesorar al cliente en la preparación de las pautas de publicidad y relaciones públicas. 
Efectuar un seguimiento y análisis de la comunicación publicitaria y no publicitaria de la competencia.

Evaluar en forma permanente la actitud de los medios de comunicación frente a las políticas y problemas específicos del cliente.

Actualizar en forma permanente la información sobre movimientos de periodistas, columnistas especializados en temas de economía y negocios y de otras áreas de interés para el cliente.

Colaborar en la definición de la política de comunicaciones y en la coordinación y difusión de eventos especiales y de promoción.

Planificar y ejecutar campañas de prensa en el interior del pais.

\section{Comunicación interna}

El público interno es, sin lugar a dudas, el más importante para la conducción de cualquier organización. Los integrantes de la empresa, en todos sus niveles, son los que hacen viable la consecución de sus objetivos. Por ello incluimos entre nuestros servicios el asesoramiento en esta área de la comunicación, especialmente en lo referido a:

- Diseño de objetivos de comunicación interna

- Formulación de planes y programas

- Evaluación del perfil actitudinal del público interno

- Programas de capacitación

- Selección de soportes y dispositivos de comunicación

- Otras actividades institucionales

Coordinar la edición de piezas editoriales que sirvan como soportes materiales de información relacionada con las actividades del cliente, como ser:

- Folleto Institucional

- House Organ

- News Letter

- Memoria Anual

- Almanaque

Desarrollar programas específicos de apoyo e intercambio con universidades nacionales y del exterior, y participar en el desarrollo de programas de formación profesional. 
Coordinar la realización de convenciones y el dictado de cursos y seminarios sobre cuestiones vinculadas con las actividades del cliente.

Promover la actividad de centros de capacitación.

\section{HERRAMIENTAS DE LA COMUNICACIÓN INSTITUCIONAL}

La comunicación en la empresa la pueden y la deben coordinar los especialistas en comunicación, pero es una responsabilidad de todos los que forman parte de ella.

Es oportuno considerar unos elementos que pueden afectar a la Comunicación y que deben asumirse previamente como esqueleto vertebrador del sistema.

Cada empresa es un mundo, con unas circunstancias absolutamente únicas incluso en el mismo sector de actividad. Lo que sirve para una, puede ser útil para otra. Esta constatación excluye explícitamente la búsqueda de manuales mágicos que sivan para todo y para todos. No existen recetas encantadas que permitan generalizar soluciones únicas a problemas concretos. Una planificación adecuada, una metodología rigurosa y un control preciso nos permitirán abordar cada caso según sus necesidades y de acuerdo con sus exigencias específicas. *( (2) MURIEL))

La comunicación interna existe por sí misma. En cualquier organización, desde el mismo momento de su constitución, se ponen en marcha todos los circuitos comunicacionales internos y externos típicos de las relaciones interpersonales. Esa inexistencia es suplida totalmente por los canales informales que tienen en el rumor, como fuente informativa, a uno de sus vicios más característicos. El rumor es una comunicación informal, a la vez producto de la actividad de comunicación del sistema social y producto de la creación de comunicación de este mismo sistema social.

Las diferentes escuelas de la comunicación empresarial lo han venido señalando desde hace muchos años: sin comunicación interna no puede haber comunicación externa.

Cada persona empleada en la empresa es un vehículo de dentro hacia fuera de la propia empresa, es decir, vende imagen empresarial.

En mi condición como profesional, considero que la comunicación al ganar un papel tan relevante en el desarrollo y competitividad del mercado, debe ocupar un alto nivel de capacitación, información y promoción en las sociedades, toda vez que es el pilar de contribución mayor en el desarrollo comercial sostenible.

\section{CONCLUSIONES}

La comunicación institucional, conjuntamente como la comunicación social y sus medios, pasan de ser una simple táctica complementaria de producción para ser ahora parte estratégica del desarrollo. 
La comunicación institucional está compuesta por diversos elementos que conjuntamente forman una imagen de la empresa que le ayuda a proyectarse tanto dentro como fuera de la empresa, en la sociedad.

Ahora ya no es suficiente que los valores existan, sino que es esencial que se revelen como tales por parte del emisor, y que de manera rápida, eficaz y certera se transmitan y sean visibles ante sus consumidores y el público en general.

"Es necesario señalar que la comunicación institucional pretende vincular su entorno empresarial junto con el contexto y significado de los mensajes, y se debe aceptar su importancia y trascendencia, además de con la relación directa que tiene con los consumidores, empleados y en sí, con la comunicación corporativa. Ahora se busca el desplazamiento de los contenidos del mensaje desde el objeto hacia el sujeto de la comunicación."

Se busca el involucrar directamente al público y los empleados, en donde haya participación constante de los consumidores y que así, la imagen de nuestra empresa crezca, sean favorables y demuestre exactamente todo lo que la empresa es.

\section{Trabajos citados}

1) VIDAL, J. R. (VIDAL, José Ramón. La Comunicación Persuasiva. Barcelona. España. Editorial Paidos, 1994. Pág. 81.

2) MURIEL, M. L.-2. (VIDAL, José Ramón. La Comunicación Persuasiva. Barcelona. España. Editorial Paidos, 1994. Pág. 81).

3) MURIEL, M. L. (MURIEL, María Luisa. ROTA, Gilda. Comunicación institucional: Enfoque social de Relaciones Públicas, Pág. 23-25.)

4) LA PORTE, J. M. (LA PORTE, José María. Perspectivas sobre Comunicación. Pontificia universidad de Santa Cruz. Facultad de Comunicación Institucional. Noviembre 2005. Pág. 1.)

5) GUISASOLA, Marisa. D. (De la imagen a la experiencia (una construcción comunicativa). Comunicación organizacional. Ponencias 2003 y 2005. Pág.1).

6) Universidad Intercontinental (Desarrollo de proyectos en Comunicación institucional.. Escuela de Ciencias de la Comunicación. Pág. 16 ).

\section{Bibliografía}


1) Universidad Intercontinental. (Desarrollo de proyectos en Comunicación institucional.. Escuela de Ciencias de la Comunicación.)

2) LA PORTE, José María. (Perspectivas sobre Comunicación. Pontificia universidad de Santa Cruz. Facultad de Comunicación Institucional. Noviembre 2005. )

3) LÓPEZ FORERO, Luis. (Introducción a los Medios de comunicación. Universidad Santo Tomas. Sexta reimpresión 1994.)

4) MURIEL, María Luisa. ROTA, Gilda. (Comunicación Institucional: Enfoque social de Relaciones Públicas.) 